\title{
Molecular modeling of electrolyte and polysulfide ions for lithium-sulfur batteries
}

\author{
Shumaila Babar ${ }^{1}$ (i) $\cdot$ Constantina Lekakou ${ }^{1}$ (D)
}

Received: 24 September 2020 /Revised: 13 November 2020 / Accepted: 28 November 2020 / Published online: 29 December 2020

(C) The Author(s) 2020

\begin{abstract}
The operation of a lithium-sulfur (Li-S) battery involves the transport of $\mathrm{Li}^{+}$ions and soluble sulfides mostly in the form of solvated ions. Key challenges in the development of Li-S battery technology are the diffusion of $\mathrm{Li}^{+}$in micropores filled with sulfur and eliminating the "shuttling" of polysulfides. Ion dimensions in solvated and desolvated forms are key parameters determining the diffusion coefficient and the rate of transport of such ions, while constrictivity effects due to the effect of pore size compared to ion size control both transport and filling of the pores. We present molecular simulations to determine the solvation parameters of electrolyte ions and sulfides $\mathrm{S}_{2}{ }^{2-}, \mathrm{S}_{4}{ }^{2-}, \mathrm{S}_{6}{ }^{2-}$, and $\mathrm{S}_{8}{ }^{2-}$ in two different electrolyte systems: LiTFSI in DOL/DME and $\mathrm{LiPF}_{6}$ in EC/DMC. The calculated parameters include the coordination number and the geometrically optimized model and dimensions, using the van der Waals surface approach, of the solvated and desolvated ions. The desolvation energy of the electrolyte ions is also calculated. Such data is useful for the modeling and design of the pore sizes of cathode host materials to be able to accommodate the different sulfides while minimizing their "shuttling" between cathode and anode.
\end{abstract}

Keywords Molecular simulations $\cdot$ Solvated ions $\cdot$ Desolvated ions $\cdot$ LiTFSI in DOL/DME $\cdot$ LiPF $_{6}$ in EC/DMC $\cdot$ Polysulfides

\section{Introduction}

Lithium-sulfur (Li-S) batteries offer the promise of high theoretical capacity, $1670 \mathrm{mAh} \mathrm{g}^{-1}$ of sulfur, but need to overcome various problems such as the "shuttling" of polysulfides [1] and cathode degradation due to volume changes during the charge-discharge cycle [2] which reduce the battery cyclability, and also diffusion of lithium ions in the case of high sulfur loading in small pores that limit $\mathrm{Li}^{+}$ion transport [3]. A typical Li-S battery consists of a lithium foil anode and a composite cathode comprising a porous carbon host impregnated by sulfur, where the carbon host provides the electronic conductivity [4], structural integrity [5], and flexibility [2] in volume changes during cycling.

The relationship between the size of the transported species and the pore size within which the transport takes place is critical with regard to both the rate of transport and filling of that pore size with the transported species. The pore size

Constantina Lekakou

c.lekakou@surrey.ac.uk

1 Materials Center, University of Surrey, Guildford, Surrey GU2 7XH, UK distribution of the porous cathode host controls the sulfur infiltration during cathode manufacture, governing which pore sizes will be filled with sulfur and which sulfur allotropes may fill different sizes, depending on the minimum molecular size of each sulfur allotrope [6]. This is expected to be repeated in polysulfide formation during battery cycling, where each type of polysulfide could not be formed in pores that cannot accommodate its size.

The importance of solvation-involved nanoionics has been recognized for various fields [7]. In $\mathrm{Li}-\mathrm{S}$ batteries, $\mathrm{Li}^{+}$ion transport is the first necessary stage for the formation of lithium sulfides in discharge. For liquid electrolytes of a lithium salt in a mixture of solvents, electrolyte ions are transported in the form of solvated ions in pores larger than the solvated ion size; for pores smaller than the solvated ion, ions are transported as desolvated ions provided that there is sufficient electrochemical energy to overcome the desolvation energy barrier [8]. In a similar manner, the "shuttling" of polysulfides in a Li-S battery depends on the ion concentration of the electrolyte and sulfide solution, which would affect the solution viscosity [8], as well as the relation between the size of the solvated or desolvated sulfide ion and the pore size that affects the diffusion coefficient $[9,10]$ which in turn controls sulfide transport via both diffusion and drift current. Ion transport 
plays an important role in the case of lean electrolyte, which, although may reduce the "shuttling" of polysulfides, may also limit $\mathrm{Li}^{+}$ion transport which is not desirable [11].

Therefore, modeling of electrolyte and sulfide ion transport would be a useful tool for the design of cathode, separator, and electrolyte materials in Li-S batteries. A continuum ion transport model taking into account the pore size distribution $[8$, 12,13 ] has been recommended for Li-S batteries [13]. Such a model requires as input data the size (minimum and maximum dimensions) of the electrolyte and polysulfide ions in desolvated and solvated forms, as well as their desolvation energy [8]. A common electrolyte in Li-S batteries is LiTFSI in DOL/DME solvent mixture (DOL: dioxolane; DME: dimethoxyethane) [14], a relatively low dielectric constant solution $\left(\varepsilon_{\mathrm{r}}=7.25\right)$ with a solubility of $6 \mathrm{M}$ to sulfur (S) species [15]. This may be compared to common electrolytes for lithium-ion batteries, such as $\mathrm{LiPF}_{6}$ in EC/DMC (EC: ethylene carbonate; DMC: dimethyl carbonate) in which the high dielectric constant of EC [16] might have further favored solubility. In this solvent mixture, cyclic polysulfide reactions between $\mathrm{S}_{8}{ }^{2-}$ sulfides and $\mathrm{S}_{3}{ }^{--}$radical anion take place at the first plateau during discharge, rather than the gradual change from $\mathrm{S}_{8}{ }^{2-}$ to $\mathrm{S}_{6}{ }^{2-}$ to $\mathrm{S}_{4}{ }^{2-}$ expected in DOL/DME solution [17]. A known disadvantage of electrolytes with carbonate solvents in Li-S batteries is the side reactions of the carbonate solvents with the dissolved polysulfides via a nucleophilic addition or substitution [18]. However, there is still great interest in carbonate-based electrolytes due to their low volatility and, hence, reduced flammability compared to the high volatility DOL/DME mixtures. Helen et al. [19] found that $\mathrm{LiPF}_{6}$ in EC/ DMC electrolyte combined with microporous carbon cathode host resulted in the formation of sulfides in the cathode host micropores in a solid or solid-liquid environment, due to the desolvation of $\mathrm{Li}^{+}$ions in the small pores: in that case, avoiding the highly solvated state of polysulfides in large pores reduced sulfide "shuttling" as well as the side reactions with the carbonate solvents. In this study, we have selected the typical LiTFSI in DOL/DME electrolyte as well as the higher dielectric constant electrolyte $\mathrm{LiPF}_{6}$ in $\mathrm{EC} / \mathrm{DMC}$.

Molecular dynamics (MD) simulations for LiTFSI in DOL:DME [20] and $\mathrm{LiPF}_{6}$ in EC/DMC [21] have provided results for the $\mathrm{Li}^{+}$ion, including the coordination number and the center-of-mass radial distribution function (RDF) between the $\mathrm{Li}^{+}$ion and solvent molecules. There is a lack of such data for polysulfides in Li-S batteries and this is addressed by the current study. Furthermore, the RDF assumes spherical solvated ions, which is not normally the case, especially for polysulfides. Markoulidis et al.'s continuum model [8] yielded good agreement between predictions of capacity in supercapacitors and experimental data when the ion dimensions in ion transport were determined from the van der Waals (VdW) surface model (or Connolly surface) of either the solvated or the desolvated ions: hence, we are also going to employ the same approach.

A large variation exists in the desolvation energy values reported in the literature for $\mathrm{Li}^{+}$ion in $\mathrm{EC} /$ $\mathrm{DMC}$, ranging from +4 to $-41.4 \mathrm{~kJ} \mathrm{~mol}^{-1}$ [22] to $-121 \mathrm{~kJ} \mathrm{~mol}^{-1}$ [23]. It is generally known that the solvated $\mathrm{PF}_{6}{ }^{-}$ion is easily desolvated in organic solvents [8]. Binding energies between $\mathrm{Li}^{+}$, TFSI ${ }^{-}$, and $\mathrm{S}_{8}{ }^{2-}$ with DME were determined using the polarizable continuum model as $-4.60,-1.79$, and $-5.85 \mathrm{eV}$ (- 443.84, 172.71, and $-564.45 \mathrm{~kJ} \mathrm{~mol}^{-1}$ ), respectively [24].

The present study includes a range of molecular simulations to determine the coordination number and the geometrically optimized model and dimensions, using the van der Waals surface approach, of the solvated and desolvated ions as well as their desolvation energy for the electrolyte cation and anion and the sulfides $\mathrm{S}_{x}{ }^{2}$ - , for $x=2-8$, in the electrolyte solvent mixture. Two electrolytes have been used: LiTFSI in DOL/DME and $\mathrm{LiPF}_{6}$ in EC/DMC. No chemical reactions have been considered in the electrolyte solution.
Table 1 Data derived from the molecular modeling of the two electrolyte systems

\begin{tabular}{|c|c|c|c|c|c|c|c|}
\hline & $\begin{array}{l}L_{\min } \\
(\mathrm{nm})\end{array}$ & $\begin{array}{l}L_{\max } \\
(\mathrm{nm})\end{array}$ & $\begin{array}{l}L_{\min , \mathrm{VdW}} \\
(\mathrm{nm})\end{array}$ & $\begin{array}{l}L_{\max , \mathrm{VdW}} \\
(\mathrm{nm})\end{array}$ & $\begin{array}{l}V_{\mathrm{VdW}} \\
\left(\mathrm{nm}^{3}\right)\end{array}$ & $N_{\mathrm{c}}$ & $\begin{array}{l}E \\
\left(\mathrm{~kJ} \mathrm{~mol}^{-1}\right)\end{array}$ \\
\hline \multicolumn{8}{|c|}{ Electrolyte LiTFSI in DOL/DME } \\
\hline $\mathrm{Li}^{+}$ & 0.18 & 0.18 & 0.18 & 0.18 & 0.00305 & & \\
\hline TFSI $^{-}$ & 0.29 & 0.76 & 0.60 & 1.05 & 0.19782 & & \\
\hline $\mathrm{Li}^{+}-\mathrm{DOL} / \mathrm{DME}$ & 0.54 & 1.26 & 0.64 & 1.48 & 0.31725 & 3 & -110 \\
\hline TFSI $^{-}$-DOL/DME & 0.61 & 1.84 & 0.77 & 1.98 & 0.78192 & 6 & -1100 \\
\hline \multicolumn{8}{|c|}{ Electrolyte $\mathrm{LiPF}_{6}$ in EC/DMC } \\
\hline $\mathrm{Li}^{+}$ & 0.18 & 0.18 & 0.18 & 0.18 & 0.00305 & & \\
\hline $\mathrm{PF}_{6}^{-}$ & 0.50 & 0.50 & 0.50 & 0.50 & 0.06541 & & \\
\hline $\mathrm{Li}^{+}-\mathrm{EC} / \mathrm{DMC}$ & 0.54 & 1.27 & 0.70 & 1.41 & 0.40806 & 4 & -67 \\
\hline $\mathrm{PF}_{6}^{-}-\mathrm{EC} / \mathrm{DMC}$ & 0.65 & 1.24 & 0.84 & 1.44 & 0.53173 & 4 & -6.7 \\
\hline
\end{tabular}


Fig. 1 3D molecular models and van der Waals surfaces of the electrolyte cation and anion for the electrolyte system LiTFSI in DOL/DME; dimensions in angstroms

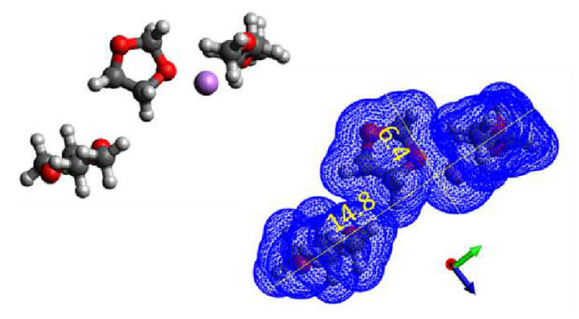

$\mathrm{Li}^{+}-\mathrm{DOL} / \mathrm{DME}$

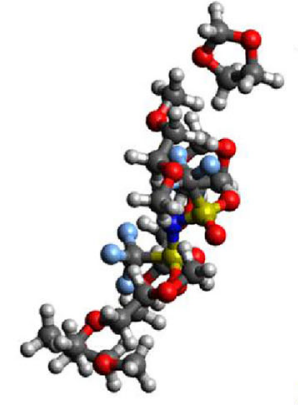

$\mathrm{TFSI}^{-}$- DOL/DME

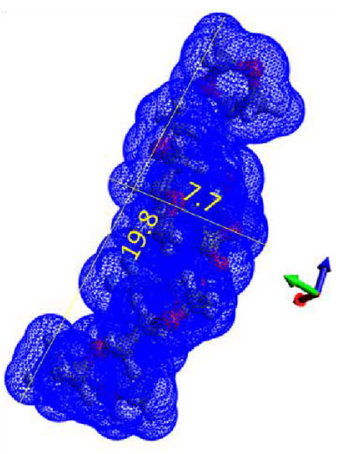

\section{Materials and methods}

Two electrolytes are considered in the simulations: LiTFSI in $\mathrm{DOL} / \mathrm{DME}$ and $\mathrm{LiPF}_{6}$ in EC/DMC. Sulfides $\mathrm{S}_{x}{ }^{2-}, x=2,4,6$, and 8 , are also included in the molecular simulation work as well as the radical anion $\mathrm{S}_{3}{ }^{-}$, which appears in cyclic polysulfide reactions near the high voltage plateau, in the presence of polar electrolyte solvents [17, 25-27] such as the EC/DMC mixture in this study.

The first phase was to determine the coordination and binding energies of each ion with each solvent by using the Blends module of Materials Studio v4.1 with base-screen pairs of solvent molecules and desolvated ions, where the desolvated ion and solvent molecule were first optimized geometrically using COMPASS, the Dreiding forcefield for TFSI, and the universal force field (UFF) potential for the $\mathrm{PF}_{6}^{-}$and polysulfide ions, and then subjected to an MD simulation. The sampling of configurations in the Blends module was carried out using the Monte Carlo method [28] where $10^{7}$ samples were employed and a reference temperature of $298 \mathrm{~K}$. Then, depending on the coordination numbers of each ion with an individual solvent, mixtures of the two solvents were created and geometrical optimization simulations were repeated with different proportions of each solvent from the solvent's mixture, until the minimum energy was reached which identified the mixture coordination number, as well as the proportion of each solvent's molecules in the solvation shell. The van der Waals surface was constructed for the final assembly of system, and from that, the maximum and minimum dimensions of the solvated or desolvated ions were determined.

\section{Results}

Table 1 presents the results for the electrolyte ions of the two electrolyte systems: LiTFSI in DOL/DME and $\mathrm{LiPF}_{6}$ in EC/ DMC. The results include the minimum and maximum dimensions, $L_{\min }$ and $L_{\max }$, of the 3D molecular models; the minimum and maximum dimensions, $L_{\min , \mathrm{VdW}}$ and $L_{\text {max,VdW }}$, of the van der Waals volumes; the coordination number $N_{\mathrm{c}}$; and the desolvation energy, $E$. There is significant difference between the dimensions of the 3D molecular models and the van der Waals volume dimensions, starting from the desolvated ions. Figure 1 and Fig. 2 present the 3D molecular models and the van der Waals volumes of the electrolyte ions of the electrolyte systems, LiTFSI in DOL/DME and $\mathrm{LiPF}_{6}$ in $\mathrm{EC} / \mathrm{DMC}$, respectively. It can be seen that the TFSI ${ }^{-}$anion is larger than the $\mathrm{Li}^{+}$cation in both desolvated and solvated forms.
Fig. 2 3D molecular models and van der Waals surfaces of the electrolyte cation and anion for the electrolyte system $\mathrm{LiPF}_{6}$ in $\mathrm{EC} / \mathrm{DMC}$; dimensions in angstroms

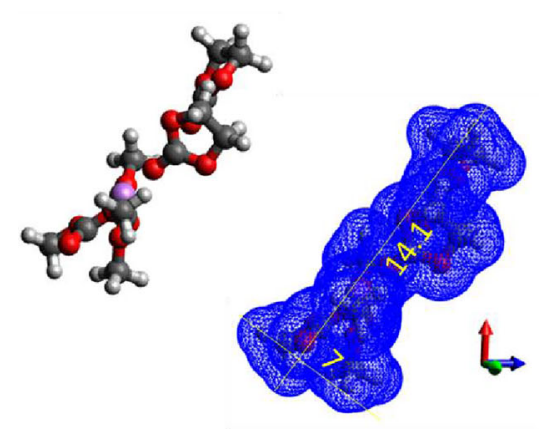

$\mathrm{Li}^{+}-\mathrm{EC} / \mathrm{DMC}$

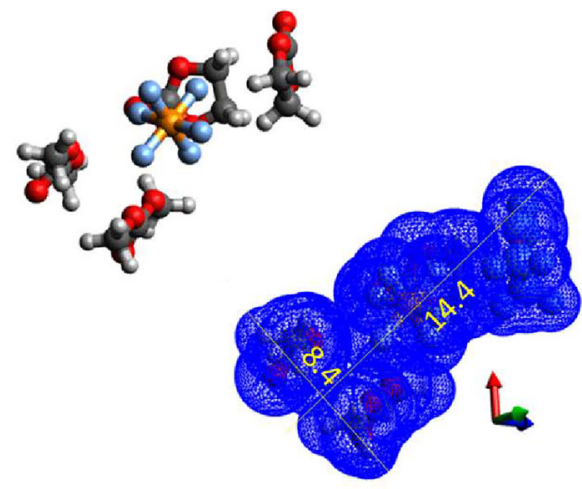

$\mathrm{PF}_{6}{ }^{-}-\mathrm{EC} / \mathrm{DMC}$ 
Table 2 Data derived from the molecular modeling of polysulfides in the two electrolyte systems

\begin{tabular}{|c|c|c|c|c|c|c|c|}
\hline \multicolumn{4}{|c|}{$\mathrm{S}_{x}^{2-}$ in DOL/DME } & \multicolumn{4}{|c|}{$\mathrm{S}_{x}{ }^{2-}$ and $\mathrm{S}_{3}{ }^{--}$in EC/DMC } \\
\hline & $L_{\mathrm{min}, \mathrm{VdW}}(\mathrm{nm})$ & $L_{\text {max }, \mathrm{VdW}}(\mathrm{nm})$ & $N_{\mathrm{c}}$ & & $L_{\text {min, } \mathrm{VdW}}(\mathrm{nm})$ & $L_{\text {max }, \mathrm{VdW}}(\mathrm{nm})$ & $N_{\mathrm{c}}$ \\
\hline \multirow[t]{2}{*}{$\mathrm{S}_{2}^{2-}$} & 0.81 & 1.36 & 4 & $\mathrm{~S}_{2}{ }^{2-}$ & 1.16 & 1.25 & 4 \\
\hline & & & & $\mathrm{S}_{3}^{--}$ & 1.0 & 1.3 & 4 \\
\hline $\mathrm{S}_{4}^{2-}$ & 1.11 & 1.50 & 5 & $\mathrm{~S}_{4}{ }^{2-}$ & 1.0 & 1.57 & 5 \\
\hline $\mathrm{S}_{6}^{2-}$ & 1.38 & 1.92 & 6 & $\mathrm{~S}_{6}{ }^{2-}$ & 0.83 & 2.25 & 6 \\
\hline $\mathrm{S}_{8}{ }^{2-}$ & 1.20 & 1.69 & 7 & $\mathrm{~S}_{8}{ }^{2-}$ & 1.58 & 2.1 & 7 \\
\hline
\end{tabular}

Table 2 presents the coordination number and van der Waals volume dimensions of the solvated sulfides in the two investigated solvents' mixture, as determined from the molecular simulations in this study. Figures 3 and 4 display the corresponding molecular models, wrapped with the van der Waals surface, for the two solvents' mixtures, LiTFSI in $\mathrm{DOL} / \mathrm{DME}$ and $\mathrm{LiPF}_{6}$ in EC/DMC, respectively. The minimum and maximum length sizes of each solvated sulfide generally decrease with decreasing sulfide order for the DOL/ DME system. There is a more uneven trend for the EC/ DMC system, as middle-order sulfides increase in their maximum dimension with increasing order but not in their minimum dimension. It must be noted that our group employs the minimum solvated ion size, $L_{\mathrm{min}, \mathrm{VdW}}$, in the Stokes-Einstein equation used in our continuum model of ion transport [8].

Finally, Fig. 5 presents the molecular models of the desolvated sulfides and their minimum and maximum dimensions. This could be of interest, as such desolvated sulfides could be formed in pores of cathode host of similar size as the desolvated sulfides, originating from the corresponding sulfur allotropes formed and trapped in these pores during cathode manufacture. In such case, the desolvated radical anion $\mathrm{S}_{3}{ }^{-{ }^{-}}$is not expected as it is the product of cyclic polysulfide reactions in the polar electrolyte solvents. However, the $\mathrm{S}_{3}{ }^{-}$molecular model and dimensions are also displayed in Fig. 5 to depict the overall picture and in case where some solvent molecules have entered the micropores causing cyclic sulfide reactions and resulting in partially solvated and desolvated products.

Figure 6 presents a summary plot of the $L_{\mathrm{min}, \mathrm{VdW}}$ and $L_{\mathrm{max}, \mathrm{VdW}}$ dimensions of all desolvated and solvated ions investigated in this study, including the electrolyte ions and polysulfides in the two electrolyte solutions: DOL/DME and
EC/DMC. There is not much difference in the dimensions of the solvated electrolyte ions between the two electrolytes, apart from the maximum dimension $L_{\mathrm{max}, \mathrm{VdW}}$ of the anion. Regarding the polysulfides, significant differences exist between the two electrolyte solutions for the solvated $\mathrm{S}_{6}{ }^{2-}$ and $\mathrm{S}_{8}{ }^{2-}$ ions.

\section{Discussion}

The calculation of the equivalent spherical diameter from the $L_{\min }$ and $L_{\max }$ dimensions of the 3D molecular model in Table 1, on the assumption of the same volume as a sphere, yields $0.72 \mathrm{~nm}$ for the solvated ion $\mathrm{Li}^{+}-\mathrm{DOL} / \mathrm{DME}$ and $0.45 \mathrm{~nm}$ for the solvated ion $\mathrm{Li}^{+}$-EC/DMC, compared to the $\mathrm{RDF}$ values predicted by MD simulations of $0.74 \mathrm{~nm}[20]$ and $0.56 \mathrm{~nm}$ [21], respectively. However, some continuum volume-averaged models of ion transport in supercapacitors and batteries, taking into account the electrode pore size distribution, prefer the van der Waals volume to the lean 3D molecular model, as the former embeds the force constraints between the moving ion and the pore walls [8]. Hence, the calculated dimensions from the van der Waals volume in this study are the preferred input data for these models.

With regard to the desolvation energies, DFT (density functional theory) simulations generally predicted high binding energy between $\mathrm{Li}^{+}$and aprotic cyclic solvents, such as $\mathrm{EC}$ and $\mathrm{DOL}$, and low binding energy between $\mathrm{Li}^{+}$and aprotic linear solvents, such as DME or DMC [29]. Given that each electrolyte system in this study comprises a mixture of cyclic and linear solvents also with a combination of different degrees of electronegativity, medium desolvation energy

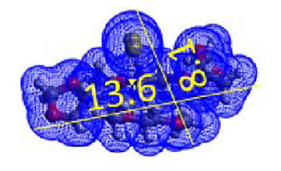

$$
\mathrm{S}_{2}{ }^{2-}-\mathrm{DOL} / \mathrm{DME}
$$
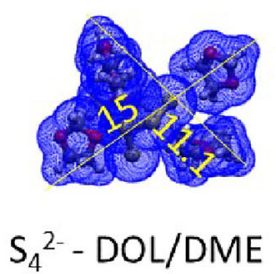

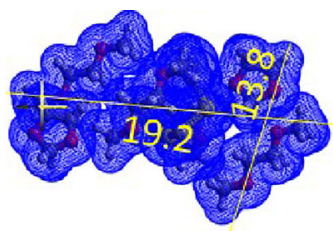

$\mathrm{S}_{6}{ }^{2-}-\mathrm{DOL} / \mathrm{DME}$

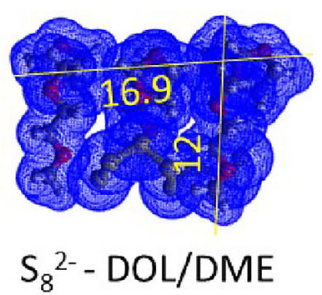

Fig. 3 3D molecular models wrapped with van der Waals surfaces of solvated polysulfide anions for the electrolyte system LiTFSI in DOL/DME; dimensions in angstroms 

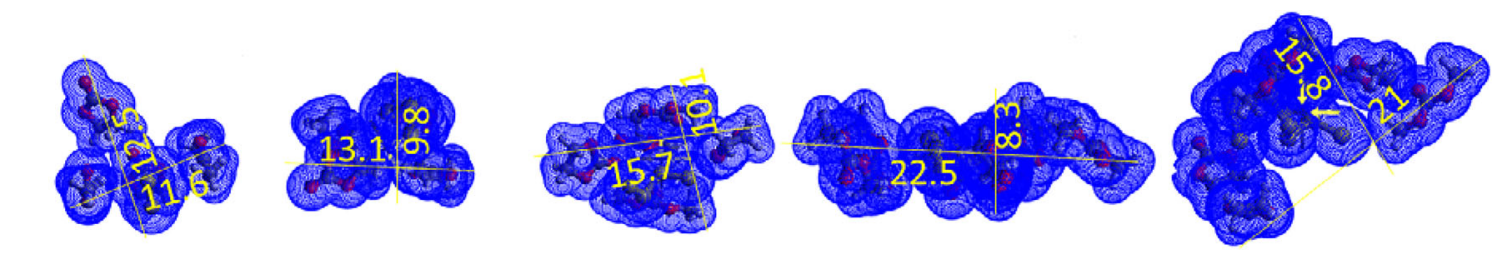

$\mathrm{S}_{2}{ }^{2-}-\mathrm{EC} / \mathrm{DMC} \quad \mathrm{S} 3^{\bullet--} \mathrm{EC} / \mathrm{DMC} \quad \mathrm{S}_{4}{ }^{2-}-\mathrm{EC} / \mathrm{DMC}$

$\mathrm{S}_{6}{ }^{2-}-\mathrm{EC} / \mathrm{DMC}$

$\mathrm{S}_{8}{ }^{2-}-\mathrm{EC} / \mathrm{DMC}$

Fig. $43 \mathrm{D}$ molecular models wrapped with van der Waals surfaces of solvated polysulfide anions for the electrolyte system $\mathrm{LiPF}_{6}$ in $\mathrm{EC} / \mathrm{DMC}$; dimensions in angstroms

values have been predicted in Table 1. This means that during the cycling of a Li-S battery, the $\mathrm{Li}^{+}$ions are likely to be able to desolvate and enter small micropores of the cathode for the maximum utilization of sulfur in discharge, while the small micropores would prevent "shuttling" of polysulfides [19].

There is a lack of data or molecular modeling predictions for the TFSI ${ }^{-}$ion; hence, our study offers a significant contribution in this area. We have predicted a high desolvation energy for TFSI ${ }^{-}$in DOL/DME; Huang et al. [30] concluded from Raman spectroscopy studies that TFSI $^{-}$in a LiTFSIDOL/DME electrolyte are strongly coordinated ions in the solvent's mixture and associated with the $\mathrm{Li}^{+}$ions as well. As TFSI $^{-}$does not participate in the redox reactions in a $\mathrm{Li}^{-}$
$\mathrm{S}$ battery, its large size as solvated ion favors the transference number of $\mathrm{Li}^{+}$ions and their ingress as desolvated cations in small micropores. On the other hand, $\mathrm{PF}_{6}{ }^{-}$has very low desolvation energy in $\mathrm{EC} / \mathrm{DMC}$, which is also confirmed from other studies in the literature [31].

The results of the molecular modeling of the solvated sulfides are of great significance as input data for the modeling of the "shuttling" of polysulfides which occurs mostly with solvated sulfides. For cathodes with sulfur impregnated in a porous host, the stage of cathode manufacture is critical in establishing the type of sulfur allotrope filling small-size micropores, as illustrated in Fig. 7a. For pores of similar size as the sulfur allotrope molecule size, such sulfur can be considered
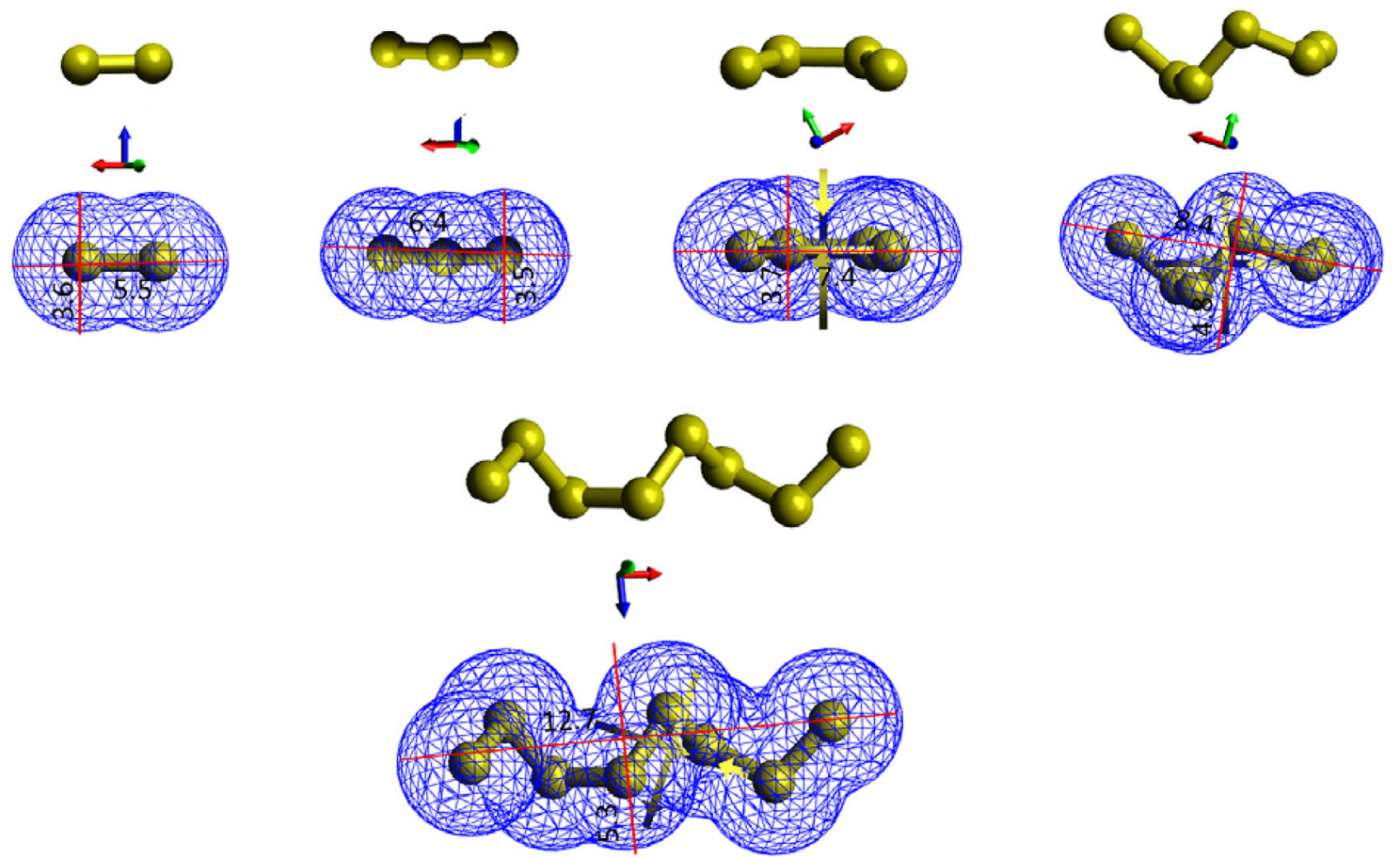

Fig. 5 3D molecular models and van der Waals surfaces of desolvated polysulfide anions and the radical anion $\mathrm{S}_{3}{ }^{-}$; dimensions in angstroms 


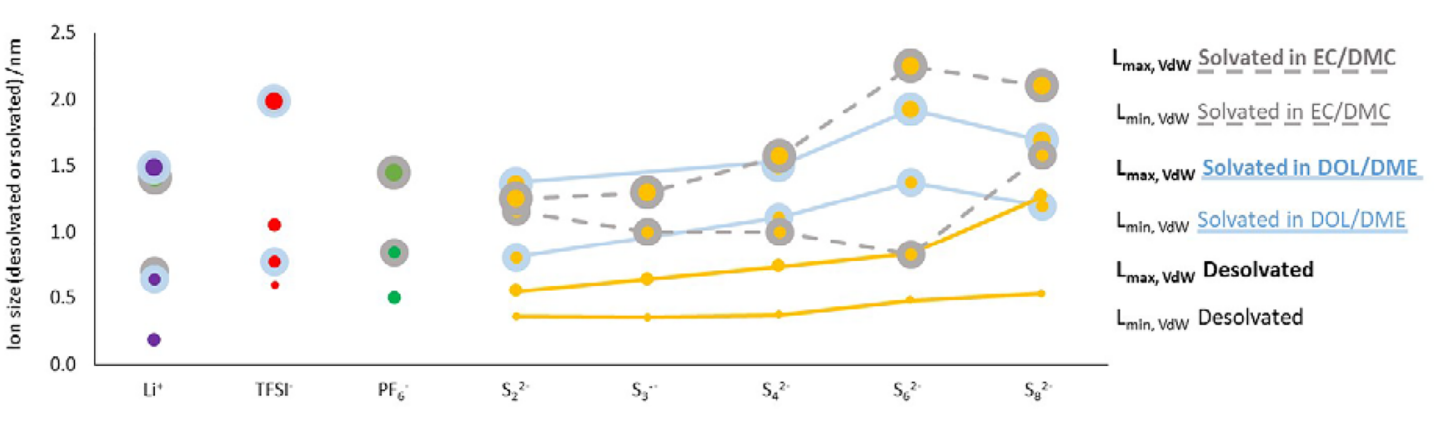

Fig. 6 A summary plot of the minimum (small symbols) and maximum ion size (large symbols), $L_{\mathrm{min}, \mathrm{VdW}}$ and $L_{\mathrm{max}, \mathrm{VdW}}$, respectively, for all ions considered in this study, in desolvated form (symbols without border) or

mostly trapped in these pores during the cycling of Li-S battery. Given that cyclic octasulfur $\mathrm{S}_{8}$ has a minimum size $L_{\text {min }}=0.7 \mathrm{~nm}[6]$, pores of $0.63 \mathrm{~nm}$, common in high surface area porous carbons [8], are not infiltrated with $\mathrm{S}_{8}$ during cathode fabrication via the sulfur melt or sublimation route but instead might be filled with lower order allotropes such as $\mathrm{S}_{4}$. As a result, such small micropores miss any reactions with $\mathrm{S}_{8}{ }^{2-}$ as the feed sulfide which generally take place at the high voltage plateau for both electrolyte systems [17] investigated in this work. Reactions at the low voltage plateau $\left(\mathrm{S}_{4}{ }^{2-}\right.$ to $S^{2-}$ ) [17] in such narrow micropores would occur in desolvated state, due to the fact that solvated sulfides do not fit in such pores as can be seen in Fig. 6. In the meso- and macropores, on the other hand, all sulfides can fit in solvated form and participate in the full reactions cascade including both high voltage and low voltage plateaus [17] but can also easily move towards the counter-charged lithium anode solvated in DOL/DME (symbols with light blue border) or EC/DMC (symbols with gray border)

during discharge. Hence, regarding the design of a porous cathode host material (Fig. 7), one has to take into account that meso- and macropores allow easy sulfide "shuttling" which reduces sulfur utilization, whereas small micropores allow only the low voltage reactions, which means lower overall energy and power, and constrict the migration of $\mathrm{Li}^{+}$, as it takes place in solid or semi-solid state, which means low $\mathrm{C}$ rate and low power. Considering Fig. 6, a pore size distribution of the cathode host including a wide peak of hierarchical pore sizes between $0.7 \mathrm{~nm}\left(L_{\min }\right.$ of $\mathrm{S}_{8}$ allotrope $)$ and $1.1 \mathrm{~nm}$ (a little lower than the solvated $\mathrm{S}_{8}{ }^{2-}$ and about same as the solvated $\mathrm{S}_{4}{ }^{2-}$ ) for DOL/DME might offer a balance of the best features of the pore sizes for DOL/DME electrolyte solution. The same pore size range may be tried also for the $\mathrm{EC} / \mathrm{DMC}$ electrolyte solution, although there is larger difference between the minimum size of the solvated ions in this case, as seen in Fig. 6, which makes more difficult to balance

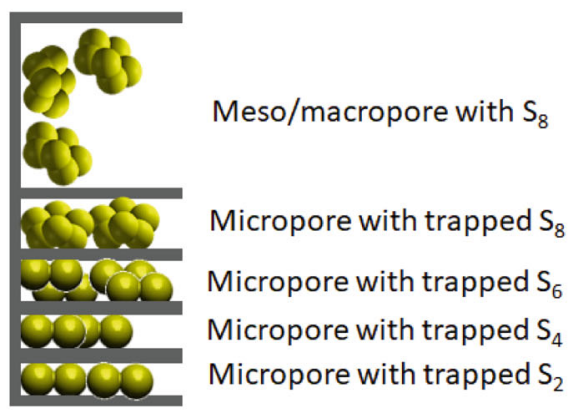

\section{MANUFACTURED CATHODE \\ WITH SULFUR IMPREGNATED \\ IN POROUS CARBON HOST}

(a)

Fig. 7 A diagram illustrating the impregnated sulfur allotropes in battery manufacture and the transport of sulfide anions in the meso- and macropores as well as the transport of the $\mathrm{Li}^{+}$ions in the discharge and

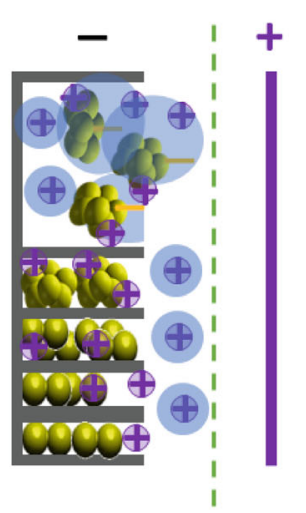

Li-S BATTERY

IN DISCHARGE

(b)

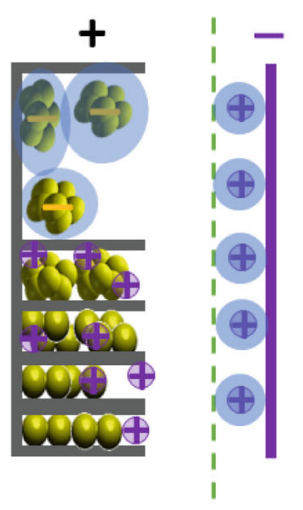

Li-S BATTERY

IN CHARGE

(c)

charge phases of a Li-S battery. a Manufactured cathode with sulfur impregnated in porous carbon host. b Li-S battery in discharge. $\mathbf{c} \mathrm{Li}-\mathrm{S}$ battery in charge 
best features of pore sizes for all sulfides. Furthermore, the additional benefit of avoiding side reactions between carbonate solvents and polysulfides in desolvated state might point towards the small micropores for EC/DMC electrolyte solution $[18,19]$.

As sulfides during discharge move out from the pores, there is no issue of desolvation. During charge (Fig. 7c), any sulfides "shuttling" back to the cathode from the anode are free to move and settle in meso- and macropores, where they react and eventually end up in the deposition of $\mathrm{S}_{8}$ there. In small micropores, where sulfide desolvation would have happened, the sulfides have already been trapped there, it is only the $\mathrm{Li}^{+}$ions that leave the small micropores during charge, to return to the lithium anode. For this reason, the value of desolvation energy of sulfides has not been deemed necessary for the modeling of the operation of Li-S batteries. On the other hand, $\mathrm{Li}^{+}$ions may be desolvated in the cathode during discharge to be able to ingress small micropores, and, hence, the solvation energy of $\mathrm{Li}^{+}$has been calculated for each system of electrolyte solvents investigated in this study.

Authors' contributions SB: simulations, analysis, and paper revision; CL: supervision, analysis, paper write up, and review.

Funding This study received funding under the Faraday project LiSTAR (EP/S003053/1, Grant FIRG014) and the EPSRC project HiPoBat (EP/ $\mathrm{R} 022852 / 1)$.

Data availability Data would be available from the corresponding author upon reasonable request.

\section{Compliance with ethical standards}

Conflict of interest The authors declare that they have no conflicts of interest.

Code availability Only commercially available codes have been used.

Open Access This article is licensed under a Creative Commons Attribution 4.0 International License, which permits use, sharing, adaptation, distribution and reproduction in any medium or format, as long as you give appropriate credit to the original author(s) and the source, provide a link to the Creative Commons licence, and indicate if changes were made. The images or other third party material in this article are included in the article's Creative Commons licence, unless indicated otherwise in a credit line to the material. If material is not included in the article's Creative Commons licence and your intended use is not permitted by statutory regulation or exceeds the permitted use, you will need to obtain permission directly from the copyright holder. To view a copy of this licence, visit http://creativecommons.org/licenses/by/4.0/.

\section{References}

1. Luo C, Hu E, Gaskell KJ, Fan X, Gao T, Cui C, Ghose S, Yang XQ, Wang C (2020) A chemically stabilized sulfur cathode for lean electrolyte lithium sulfur batteries. PNAS 117:14712-14720. https://doi.org/10.1073/pnas.2006301117

2. Shaibani M, Mirshekarloo MS, Singh R, Easton CD, Cooray MCD, Eshraghi N, Abendroth T, Dörfler S, Althues H, Kaskel S, Hollenkamp AF, Hill MR, Majumder M (2020) Expansiontolerant architectures for stable cycling of ultrahigh-loading sulfur cathodes in lithium-sulfur batteries. Sci Adv 6:1-11. https://doi.org/ 10.1126/sciadv.aay2757

3. Hu, Y, Chen, W, Lei, T, Jiao, Y, Huang, J, Hu, A, Gong, C, Yan, C, Wang, X, Xiong, J (2020) Strategies toward high-loading lithiumsulfur battery. Adv. Energy Materials 10: 2000082/1-19. https:// doi.org/10.1002/aenm.202000082

4. Di Lecce, D, Marangon, V, Du, W, Brett, D, Shearing, R, Hassoun, $J(2020)$ The role of synthesis pathway on the microstructural characteristics of sulfur-carbon composites: X-ray imaging and electrochemistry in lithium battery. Journal of Power Sources 472: 228424/12-13. https://doi.org/10.1016/j.jpowsour.2020.228424

5. Elazari R, Salitra G, Garsuch A, Panchenko A, Aurbach D (2011) Sulfur-impregnated activated carbon fiber cloth as a binder-free cathode for rechargeable Li-S batteries. Adv Mater 23:56415644. https://doi.org/10.1002/adma.201103274

6. Lasetta, K, Baboo, JP, Lekakou, C (2020) Modeling and simulations of the sulfur infiltration in activated carbon fabrics during composite cathode fabrication for lithium-sulfur batteries. Journal of Composites Science, submitted August 2020

7. Zhan H, Xiong, Z, Cheng, C, Liang, Q, Liu, JZ, Li, D (2020) Solvation-involved nanoionics: new opportunities from $2 \mathrm{~d}$ nanomaterial laminar membranes. Adv Mat, 32: 1904562/1-16. https://doi.org/10.1002/adma.201904562

8. Markoulidis F, Bates J, Lekakou C, Slade R, Laudone GM (2020) Supercapacitors with lithium-ion electrolyte: an experimental study and design of the activated carbon electrodes via modelling and simulations. Carbon 164:422-434. https://doi.org/10.1016/j. carbon.2020.04.017

9. Sahapatsombut U, Cheng H, Scott K (2014) Modelling of operation of a lithium-air battery with ambient air and oxygen-selective membrane. J Power Sources 249:418-430. https://doi.org/10.1016/j. jpowsour.2013.10.128

10. Beck RE, Schultz JS (1970) Hindered diffusion in microporous membranes with known pore geometry. Science 170:1302-1305. https://doi.org/10.1126/science.170.3964.1302

11. Zhao M, Li B, Peng H, Yuan H, Wei J, Huang J (2020) Lithiumsulfur batteries under lean electrolyte conditions: challenges and opportunities. Angew Chem 59:3-6. https://doi.org/10.1002/anie. 201909339

12. Minton G, Purkayastha R, Lue L (2017) A non-electroneutral model for complex reaction-diffusion systems incorporating species interactions. J Electrochem Soc 164:E3276-E3290. https://doi.org/ 10.1149/2.0281711jes

13. Babar, S, Zhang, T, Lekakou, C (2020) 12- Molecular and mesoscale models for Li-S cells, in Roadmap IoP paper, J. Phys.: Energy 2, submitted July 2020

14. Manthiram A, Chung S-H, Zu C (2015) Lithium-sulfur batteries: progress and prospects. Adv, Mat 25:1980-2006. https://doi.org/ 10.1002/adma.201405115

15. Gupta, A, Bhargav, A, Manthiram, A (2019) Highly solvating electrolytes for lithium-sulfur batteries. Adv Energy Mater 9: 2018030961/1-17. https://doi.org/10.1002/aenm.201803096

16. Han, S (2019) Structure and dynamics in the lithium solvation shell of nonaqueous electrolytes. Sci Rep 9: 5555/1-10. https://doi.org/ 10.1038/s41598-019-42050-y

17. Lu Y-C, He Q, Gasteiger HA (2014) Probing the lithium-sulfur redox reactions: a rotating-ring disk electrode study. J Phys Chem C 118:5733-5741. https://doi.org/10.1021/jp500382s

18. Gao J, Lowe MA, Kiya Y, Abruña HD (2011) Effects of liquid electrolytes on the charge-discharge performance of rechargeable 
lithium/sulfur batteries: electrochemical and in-situ x-ray absorption spectroscopic studies. J Phys Chem C 115:25132-25137. https://doi.org/10.1021/jp207714c

19. Helen M, Diemant T, Schindler J, Behm RJ, Danzer M, Kaiser U, Fichtner M, Reddy MA (2018) Insight into sulfur confined in ultramicroporous carbon. ACS Omega 3:11290-11299. https:// doi.org/10.1021/acsomega.8b01681

20. Park C, Kanduc M, Chudoba R, Arne Ronneburg A, Risse S, Ballau M, Dzubiellaa J (2018) Molecular simulations of electrolyte structure and dynamics in lithium-sulfur battery solvents. J Power Sources 373:70-78. https://doi.org/10. 1016/j.jpowsour.2017.10.081

21. Tenney CM, Cygan RT (2013) Analysis of molecular clusters in simulations of lithium-ion battery electrolytes. J Phys Chem C 117(2013):24673-24684. https://doi.org/10.1021/jp4039122

22. Borodin O, Olguin M, Ganesh P, Kent PRC, Allen JL, Henderson WA (2016) Competitive lithium solvation of linear and cyclic carbonates from quantum chemistry. Phys Chem Chem Phys 18:164175. https://doi.org/10.1039/C5CP05121E

23. Ponnuchamy V (2015) Towards a better understanding of lithium ion local environment in pure, binary and ternary mixtures of carbonate solvents : a numerical approach. PhD Thesis, Université Grenoble Alpes, France

24. Sun K, Wu Q, Tong X, Gan H (2018) Electrolyte with low polysulfide solubility for Li-S batteries. ACS Appl Energy Mater 1: 2608-2618. https://doi.org/10.1021/acsaem.8b00317

25. Cuisinier M, Hart C, Balasubramanian M, Garsuch A, Nazar LF (2015) Radical or not radical: revisiting lithium-sulfur electrochemistry in nonaqueous electrolytes. Adv Energy Mater 5:1401801/11401801/6. https://doi.org/10.1002/aenm.201401801
26. Shyamsunder A, Beichel W, Klose P, Pang Q, Scherer H, Hoffmann A, Murphy GK, Krossing I, Nazar LF (2017) Inhibiting polysulfide shuttle in lithium-sulfur batteries through low-ion-pairing salts and a triflamide solvent. Angew Chem 56: 6192-6197. https://doi.org/10.1002/anie.201701026

27. Zhang G, Peng H-J, Zhao C-Z, Chen X, Zhao L-D, Li P, Huang JQ, Zhang Q (2018) The radical pathway based on a lithium-metalcompatible high-dielectric electrolyte for lithium-sulfur batteries. Angew Chem 57:16732-16736. https://doi.org/10.1002/anie. 201810132

28. Akkermans RLC, Spenley NA, Robertson SH (2013) Monte Carlo methods in materials studio. Mol Simul 39:1153-1164. https://doi. org $/ 10.1080 / 08927022.2013 .843775$

29. Gering KL (2006) Low-temperature performance limitations of lithium-ion batteries. ECS Trans 1:119-149. https://doi.org/10. $1149 / 1.2209364$

30. Huang F, Gao L, Zou Y, Ma G, Zhang J, Xu S, Li ZX, Liang X (2019) Akin solid-solid biphasic conversion of a Li-S battery achieved by coordinated carbonate electrolytes. J Mater Chem A 7:12498-12506. https://doi.org/10.1039/C9TA02877C

31. Ong MT, Verners O, Draeger EW, van Duin ACT, Lordi V, Pask JF (2015) Lithium ion solvation and diffusion in bulk organic electrolytes from first principles and classical reactive molecular dynamics. Phys Chem B 119:1535-1545. https://doi.org/10.1021/ jp508184f

Publisher's note Springer Nature remains neutral with regard to jurisdictional claims in published maps and institutional affiliations. 